\title{
Left ventricular hypertrophy in hypertension: Correlation between electrocardiography and echocardiography
}

\author{
Prakash O', Karki P², Sharma SK
}

${ }^{1}$ Department of Internal Medicine, College of Medical Sciences, Bharatpur, Nepal, ${ }^{2}$ Department of Internal Medicine, B.P. Koirala Institute of Health Sciences, Dharan, Nepal

\begin{abstract}
Background: Hypertension is an important modifiable cardiovascular risk factor. Left ventricular hypertrophy - the marker of hypertension, has emerged as an independent risk factor that can be detected by electrocardiography (ECG) and echocardiography (ECHO).

Objective: Correlation of electrocardiography and echocardiographically detected left ventricular hypertrophy in hypertensive patients.

Materials and methods: Hundred patients with hypertension were studied for left ventricular hypertrophy by the help of electrocardiography and echocardiography. Left ventricular hypertrophy on ECG was assessed by the help of SokolowLyon Voltage Criteria (SLV) and Romhilt - Estes Point Score (R/E).

Results: Among 100 patients, 60 were males and 40 were females. Mean age for male was $54.82 \pm 12.10$ years and $52.95 \pm 11.63$ years for female.

The mean systolic blood pressure for male was $150.47 \pm 20 \mathrm{mmHg}$ and for female $148.60 \pm 16.95 \mathrm{mmHg}$; where as Diastolic blood pressure for male was $93.67 \pm 11.13 \mathrm{mmHg}$ and for female it was $96.05 \pm 12.47 \mathrm{mmHg}$.

Echocardiography detected left ventricular hypertrophy in 64\% patients. Electrocardiography detected Left Ventricular Hypertrophy by R/E and SLV criteria $13 \%$ and $34 \%$ respectively.

Conclusion: In developing and under developed country ECG is a useful tool for detection of LVH where the facilities of echocardiography and trained echocardiographer are still not in a common man's reach.
\end{abstract}

Key words: Left ventricular hypertrophy, Hypertension

$\mathrm{H}$ ypertension is one of the important public health problems. Hypertension is defined as the presence of a blood pressure elevated to a level that places patients at increased risk for target organ damage in several vascular beds. Clinically hypertension is characterised by a blood pressure more than $140 / 90 \mathrm{mmHg}^{1}$.

It is estimated that the life time probability of development of hypertension is $90 \%$ for individuals aged 55-65 years of age in western countries ${ }^{1}$.

It is common, asymptomatic, readily detectable, usually easily treatable, and often leads to lethal complication if left untreated ${ }^{2}$.

Framingham heart study and as well as various other studies have shown that left ventricular hypertrophy which can be detected by electrocardiography and echocardiography has emerged as an independent risk factor, for the cardiovascular morbidity and mortality $^{3,4,5}$.
In 1979, The Framingham Heart Study incorporated echocardiography into the assessment of cardiovascular risk and subsequently demonstrated the prognostic importance of increased left ventricular mass ${ }^{6}$.

Although left ventricular hypertrophy is an infrequent finding on the electrocardiography, it is a forerunner of coronary disease, congestive cardiac failure, stroke and even peripheral arterial disease. Despite being strongly related to hypertension left ventricular hypertrophy remains associated with excess risk for adverse cardiovascular morbidity and fatal outcomes even after adjusting for blood pressure?

The most readily available diagnostic modality for left ventricularhypertrophyhasbeentheelectrocardiography. Most physicians have relied on it to detect the presence of left ventricular hypertrophy in hypertensive.

\footnotetext{
Correspondence

Dr. Om Prakash

Department of Internal Medicine, C.M.S., Bharatpur

E-mail: omprakashdr@gmail.com
} 
The present study was undertaken because of lack of data regarding similar studies in South Asian countries particularly in Nepal, where it is all the more important due to lack of resources, and expensive investigations like echocardiography is out of common man's reach.

\section{Aims and objectives hypertension in eastern Nepal. \\ Electrocardiography criteria used were \\ 1. Romhilt - Estes Point Score ${ }^{8}$. \\ 2. Sokolow - Lyon Voltage Criteria9 .}

The objective of the study was to see the correlation between electrocardiography and echocardiography for the detection of left ventricular hypertrophy in

\section{Material and methods}

Hundread patients with blood pressure more than $140 / 90 \mathrm{mmHg}$ or a known hypertensive on treatment as per the JNC VII guidelines were studied ${ }^{10}$.

Patients with complete bundle branch block, evidence of myocardial infarction, WolfParkinson White Syndrome, Atrial fibrillation on ECG were excluded from the study. Also all patients with regional wall motion abnormality, Ventricular Aneurysm, severe Right Ventricular volume overload, Hypertrophic Cardiomyopathy, Aortic Stenosis by ECHO were excluded from the study.

Linear regression was used to see the correlation between the two ECG criteria and ECHO. All calculation was done with the help of SPSS version 10.0 programs and EPI info 2000 software packages.

\section{Procedure}

The study was conducted at Department of Internal Medicine, BPKIHS on 100 hypertensive patients. Patients were enrolled from outpatient and in patients department on serial basis from $1^{\text {st }}$ June 2003 to $31^{\text {st }}$ may 2004.

Hundred and six hypertensive patients satisfying the above inclusion and exclusion criteria were consider for the study. Six were excluded due to poor cardiac window during the echocardiography.

Blood pressure was taken with the help of mercury sphygmomanometer based on the latest recommendation by the Seventh Report of the Joint National Committee on prevention, detection, evaluation, and treatment of high Blood Pressure ${ }^{10}$.

Obesity was defined according to the body mass index, which was calculated by dividing body weight $(\mathrm{kg})$ by height $\left(\mathrm{m}^{2}\right)^{11}$.
Smoking was defined in case a subject was smoking at least 5 or more bidi, cigarette, hukka, for 5 years or more. Similarly patient was considered consuming alcohol in case his regular drink (local alcohol/Bear/ Wine) comprised more than $100 \mathrm{ml}$ per day for more than five years ${ }^{12}$.

After informed consent relevant brief history and cardiovascular examination was done. The height $(\mathrm{Cm})$ and weight $(\mathrm{Kg})$ were measured and Body Surface Area was calculated using the formula ${ }^{13}$.

BSA $\left(\mathrm{m}^{2}\right)=[\text { Height }(\mathrm{Cm})]^{0.718} \mathrm{x}[\text { Weight }(\mathrm{Kg})]^{0.427} \mathrm{x}$ 0.007449

Twelve lead electrocardiography was done with Nihon Kohden electrocardiographic machine, cardio fax, ECG $882 \mathrm{OK}$. Twelve leads electrocardiography was recorded at the paper speed of $25 \mathrm{~mm} / \mathrm{second}$ and calibration of $10 \mathrm{~mm}$ was taken as a standard electrocardiogram ${ }^{14}$.

Electrocardiographic criteria used to diagnose left ventricular hypertrophy were:

\section{Romhilt - Estes Point Score ${ }^{8}$}

Methods

Score

1.Increased QRS Amplitude (Any of the following)

$\mathrm{R}$ or $\mathrm{S}$ in limb lead

$\mathrm{S}$ in $\mathrm{V}_{1}$ or $\mathrm{V}_{2}$,

$\mathrm{R}$ in $\mathrm{V}_{5}$ or $\mathrm{V}_{6}$

$$
\left.\begin{array}{l}
\geq 20 \mathrm{~mm} \\
\geq 30 \mathrm{~mm} \\
\geq 30 \mathrm{~mm}
\end{array}\right\}
$$

2. Any ST Shift (Opposite to QRS direction)

3. Left Axis Deviation $\geq-30^{\circ}$

4. QRS interval > .09 Sec

5. Intrinsicoid deflection in $\mathrm{V}_{5} / \mathrm{V}_{6} \geq 0.04$ Sec.

(Time measured from the beginning of the QRS

Complex to the apex of the R Wave)

6. P-terminal force in $\mathrm{V} 1 \geq .04 \mathrm{Sec}$.

(A-P wave of left atrial enlargement

$\mathbf{L V H} \geq \mathbf{5 . 0}$

\section{Sokolow and Lyon Voltage Criteria9.}

1. R wave in $\mathrm{V}_{5}$ or $\mathrm{V}_{6}>26 \mathrm{~mm}$

$$
\text { And / or }
$$

2. Sum of $\mathrm{S}$ wave in lead $\mathrm{V}_{1}+\mathrm{R}$ wave in $\mathrm{V}_{5}$ or $\mathrm{V}_{6}$ $>35 \mathrm{~mm}$

Following investigations; the two electrocardiographic criteria was used to diagnose Left ventricular hypertrophy and was compared with echocardiographic criteria. Later on these patients were studied using 
standard M-mode echocardiography (Hewlett Packard Sonos1800). Person performing ECHO was blinded to electrocardiographic findings. Patients were studied supine or in left lateral decubitus position with transducer placement in the $3^{\text {rd }}$ to $5^{\text {th }}$ intercostal space.

Measurementobtainedbywayofstandardsrecommended by the American Society of Echocardiography ${ }^{15}$.

\section{Left Ventricular Posterior Wall Thickness in diastole (LVPWTd)}

Represent the distance between the leading edge of the posterior left ventricular endocardium and the leading edge of the epicardium at the $\mathrm{R}$ wave of the electrocardiogram.

\section{Inter Ventricular Septal Thickness in diastole (IVSTd)}

Wall thickness is the distance between the leading edge of the left septal echo and the trailing edge of the right septal echo at the $\mathrm{R}$ wave of the electrocardiogram.

\section{Left Ventricular Internal Dimension in the diastole (LVIDd)}

Measure the trailing edge of the left side of the septum to the leading edge of the posterior endocardium at the $\mathrm{R}$ wave of the electrocardiogram.

\section{Left Ventricular Mass (LVM) was calculated using Devereux formula ${ }^{16}$. LVM=1.04 (LVIDd + IVSTd + LVPWTd $)^{3}-(\text { LVIDd })^{3}$ - 13.6gms.}

Because left ventricular mass varies directly with the body surface Area, it was commonly indexed for this measure of body size. This was left ventricular mass index (LVMI) expressed in gram/ meter square.

LVMI $\left(\operatorname{gram} / \mathrm{m}^{2}\right)=$ LVM/BSA

The upper limit of normal left ventricular mass index for male was defined as $116.07 \mathrm{gm} / \mathrm{m}^{2}$ and for female as $104.36 \mathrm{gm} / \mathrm{m}^{2}$ which is taken as a standard in this study $^{17}$.

\section{Results}

Out of hundred patients studied the mean age of hypertensive subjects was 54.07 years. The mean age of males and females was 54.82 years and 52.95 years respectively. The mean body mass index was 25.02 $\mathrm{kg} / \mathrm{m}^{2}$ which were more in females $27.19 \mathrm{~kg} / \mathrm{m}^{2}$ then males $23.57 \mathrm{~kg} / \mathrm{m}^{2}$. The mean systolic blood pressure was $149.72 \mathrm{mmHg}$. The mean systolic blood pressure of males was $150.47 \mathrm{mmHg}$ and of females was 148.60 $\mathrm{mmHg}$. The mean diastolic blood pressure was 94.62 $\mathrm{mmHg}$; which was more in females $96.05 \mathrm{mmHg}$ then males $93.67 \mathrm{mmHg}$. The characteristics of the hundred patients are shown in Table 1.
Echocardiography detected various measurements are shown in the Table 2.

Echocardiographically detected mean of left ventricular mass was $220.80 \mathrm{gm}$ which was more in males 231.10 $\mathrm{gm}$ then that in females $205.35 \mathrm{gm}$. The mean of left ventricular mass index was $133.70 \mathrm{~g} / \mathrm{m}^{2}$ which were more in the males $136.70 \mathrm{~g} / \mathrm{m}^{2}$ then females $129.21 \mathrm{~g} /$ $\mathrm{m}^{2}$.

Sensitivity and specificity of electrocardiographic criteria are shown in the Table 3.

Echocardiography detected left ventricular hypertrophy in $64 \%$ of patients in our study.

The sensitivity and specificity of Romhilt-Estes Point Scoring System was $14 \%$ and $88 \%$ respectively, keeping the echocardiographic diagnostic criteria as gold standard and for Sokolow-Lyon Voltage Criteria it was $28 \%$ and $55 \%$ respectively.

The sensitivity and specificity of electrocardiographic criteria were further influenced by other determinants of left ventricular hypertrophy as shown in Table 4 and Table 5.

\section{Classification of Blood Pressure Level}

Patients with hypertension were classified into group I and group II; and compared for the detection of the Left Ventricular Hypertrophy by the electrocardiography criteria and the echocardiographically as shown in the Table 6.

Out of 100 patients 57 had stage I hypertension and 43 were in stage II hypertension. In stage I, 22 were detected to have LVH by SLV criteria where as 13 were detected by the R/E criteria.

37 patients had LVH by echocardiography. In stage II hypertension, 12 were detected having LVH by SLV criteria where as $\mathrm{R} / \mathrm{E}$ criteria could not detect any one. 27 patients had LVH by echocardiography.

\section{Electrocardiographic Correlations}

Correlation between the two Electrocardiographic criteria and left Ventricular Mass/Left Ventricular Mass index was done using Karl Pearson Co-efficient of Correlation as shown in the Table 7.

This correlation was statistically not significant.

Linear Regression Analysis was performed comparing M-mode echocardiographically predicted Mass with electrocardiographic criteria used for diagnosis of left ventricular hypertrophy. 
It was noted that Sokolow-Lyon Voltage Criteria did not correlate with echocardiographic Left Ventricular mass $(\mathrm{r}=-0.025 ; \mathrm{P}=0.806)$.
It was also observed that Romhilt - Estes Point Scoring System also did not correlate with the echocardiographic Left Ventricular Mass $(\mathrm{r}=0.072 ; \mathrm{P}=0.476)$

Table 1: The Characteristics of the Patients in the Study Population

\begin{tabular}{|l|c|c|c|}
\hline CHARACTERS & Total $(\mathbf{n}=\mathbf{1 0 0})$ & Male $(\mathbf{n}=\mathbf{6 0})$ & Female $(\mathbf{n}=\mathbf{4 0})$ \\
\hline Age $(\mathrm{yr})$ & $54.07 \pm 11.89$ & $54.82 \pm 12.10$ & $52.95 \pm 11.63$ \\
\hline BMI $\left(\mathrm{kg} / \mathrm{m}^{2}\right)$ & $25.02 \pm 5.31$ & $23.57 \pm 5.17 .00$ & $27.19 \pm 04.80$ \\
\hline SBP $(\mathrm{mmHg})$ & $149.72 \pm 18.78$ & $150.47 \pm 20.00$ & $148.60 \pm 16.95$ \\
\hline DBP $(\mathrm{mmHg})$ & $94.62 \pm 11.68$ & $93.67 \pm 11.13$ & $96.05 \pm 12.47$ \\
\hline
\end{tabular}

Table 2: Echocardiography Findings According to Gender

\begin{tabular}{|l|c|c|c|}
\hline VARIABLE & Total $(\mathbf{n}=\mathbf{1 0 0})$ & Male $(\mathbf{n}=\mathbf{6 0})$ & Female $(\mathbf{n}=\mathbf{4 0})$ \\
\hline IVSD & $1.14 \pm 0.35$ & $1.18 \pm 0.37$ & $1.08 \pm 0.29$ \\
\hline LVIDD & $4.53 \pm 0.86$ & $4.50 \pm 0.80$ & $4.55 \pm 0.94$ \\
\hline LVPWTD & $1.11 \pm 0.29$ & $1.14 \pm 0.30$ & $1.05 \pm 0.25$ \\
\hline LVM $(\mathrm{g})$ & $220.80 \pm 90.42$ & $231.10 \pm 100.32$ & $205.35 \pm 71.57$ \\
\hline LVMI $\left(\mathrm{g} / \mathrm{m}^{2}\right)$ & $133.70 \pm 54.78$ & $136.70 \pm 60.46$ & $129.21 \pm 45.31$ \\
\hline
\end{tabular}

Table 3: Sensitivity and specificity of electrocardiographic criteria

\begin{tabular}{|l|c|c|c|c|c|c|c|}
\hline TEST & Sensitivity $\%$ & Specificity $\%$ & P value & Odds ratio & 95\% CI & PPV \% & NPV \% \\
\hline ROMHILT & 14 & 88 & 0.673 & 1.31 & $0.33-5.55$ & 69 & 36 \\
\hline SOKOLOW & 28 & 55 & 0.109 & 0.50 & $0.19-1.28$ & 52 & 30 \\
\hline
\end{tabular}

Table 4: Sokolow-Lyon Voltage Criteria

\begin{tabular}{|l|c|c|c|c|c|c|c|}
\hline DETERMINANTS & $\begin{array}{c}\text { Sensitivity } \\
(\mathbf{\%})\end{array}$ & $\begin{array}{c}\text { Specificity } \\
(\mathbf{\%})\end{array}$ & P value & Odds ratio & $\mathbf{9 5 \%}$ CI & $\begin{array}{c}\text { PPV } \\
(\%)\end{array}$ & $\begin{array}{c}\text { NPV } \\
(\%)\end{array}$ \\
\hline Male & 34 & 45 & 0.123 & 0.43 & $0.47-1.44$ & 52 & 28 \\
\hline Female & 19 & 71 & 0.499 & 0.60 & $0.10-3.44$ & 55 & 32 \\
\hline Smoker & 22 & 54 & 0.189 & 0.34 & $0.05-2.25$ & 44 & 30 \\
\hline Non-smoker & 30 & 56 & 0.253 & 0.56 & $0.18-1.72$ & 56 & 30 \\
\hline Alcoholic & 42 & 50 & 0.708 & 0.75 & $0.13-4.34$ & 64 & 29 \\
\hline Non-alcoholic & 20 & 57 & 0.057 & 0.36 & $0.11-1.19$ & 45 & 30 \\
\hline
\end{tabular}

Table 5: Romhilt-Estes Point Scoring System

\begin{tabular}{|l|c|c|c|c|c|c|c|}
\hline DETERMINANTS & $\begin{array}{c}\text { Sensitivity } \\
(\mathbf{\%})\end{array}$ & $\begin{array}{c}\text { Specificity } \\
(\mathbf{\%})\end{array}$ & P value & Odds ratio & $\mathbf{9 5 \%}$ CI & $\begin{array}{c}\text { PPV } \\
(\%)\end{array}$ & $\begin{array}{c}\text { NPV } \\
(\%)\end{array}$ \\
\hline Male & 13 & 81 & 0.599 & 0.68 & $0.13-3.54$ & 55 & 35 \\
\hline Female & 15 & 100 & 0.121 & 0.61 & $0.47-0.79$ & 100 & 38 \\
\hline Smoker & 11 & 81 & 0.592 & 0.56 & $0.04-7.02$ & 50 & 36 \\
\hline Non-smoker & 15 & 92 & 0.382 & 2.06 & $0.34-15.81$ & 77 & 37 \\
\hline Alcoholic & 28 & 80 & 0.610 & 1.60 & $0.20-14.83$ & 75 & 34 \\
\hline Non-alcoholic & 6 & 92 & 0.911 & 0.90 & $0.11-8.41$ & 60 & 37 \\
\hline
\end{tabular}

Table 6: Classification of Blood Pressure Level

\begin{tabular}{|c|c|c|c|c|}
\hline Stage & No. of Patients & SLV-criteria & R \& E-criteria & LVMI $\left(\mathbf{g m} / \mathbf{m}^{\mathbf{2}}\right)$ \\
\hline I & 57 & 22 & 13 & 37 \\
\hline II & 43 & 12 & 0 & 27 \\
\hline
\end{tabular}


Table 7: Correlation between electrocardiography and echocardiography

\begin{tabular}{|c|c|c|c|}
\hline \multicolumn{2}{|c|}{} & LVM (gm) & LVMI (gm/ $\left.\mathbf{m}^{\mathbf{}}\right)$ \\
\hline \multirow{2}{*}{$\begin{array}{c}\text { Pearson } \\
\text { Correlation (r) }\end{array}$} & R\&E & 0.072 & 0.135 \\
\cline { 2 - 4 } & SLV & -0.025 & 0.076 \\
\hline \multirow{2}{*}{ Significance (p) } & R\&E & 0.476 & 0.182 \\
\cline { 2 - 4 } & SLV & 0.806 & 0.454 \\
\hline
\end{tabular}

\section{Discussion}

The Romhilt- Estes Point Scoring System, first devised from an analysis of the electrocardiographic changes noted in left ventricular hypertrophy, was originally reported to be $60 \%$ sensitive and $95 \%$ specific in diagnosing left ventricular hypertrophy ${ }^{8}$.

In our study the sensitivity was only $14 \%$ but specificity was $88 \%$. The specificity was almost similar but the sensitivity was much lower in our study. This was probably because the determinants of left ventricular hypertrophy like age, sex, and blood pressure level, duration of hypertension and use of antihypertensive drugs were not taken into consideration. Although other Point Scoring Systems have been proposed, they have no advantage over the Romhilt- Estes Point Score in diagnosing left Ventricular Hypertrophy.

Our study data confirms that Romhilt - Estes Point Score System is specific but not sensitive

Sokolow-Lyon in their original study claimed that the sensitivity of their Voltage Criteria was $32 \%$ and specificity $100 \%{ }^{9}$.

Our study showed an almost similar sensitivity (28\%) but specificity $(55 \%)$ was much lower in our study. It may be due to the body mass index which is less in Asian countries compared to Western countries.

Our study data on Sokolow-Lyon Voltage Criteria supports the widespread impression that it is more sensitive and less specific than Romhilt -Estes Point Score System

Echocardiographically detected left ventricular hypertrophy has been found to be $93 \%$ sensitivity and $95 \%$ specificity in previous studies by using Devereux formula ${ }^{18}$.

In our study the sensitivity for detection of left ventricular hypertrophy by echocardiography was $64 \%$.

In this study, it was showed that sensitivity, specificity and accuracy obtained using echocardiographic criteria for diagnosis of left ventricular hypertrophy when compared with anatomic left ventricular mass; clearly show that this method is highly reliable. Nixon has also confirmed the reliability of this method angiographically ${ }^{19}$.

Okin PM found that electrocardiographic criteria for left ventricular hypertrophy has lower sensitivity in women when compared to men even when the gender differences like left ventricular mass, height and weight were taken into account ${ }^{20}$.

In our study also a similar trend was observed with Sokolow-Lyon voltage criteria but not with the Romhilt-Estes Point Scoring system. However, it was statistically not significant.

Schillaci G showed that electrocardiography had lower sensitivity for diagnosing left ventricular hypertrophy in hypertensive smokers when compared to hypertensive non smokers ${ }^{21}$.

Our study showed that the sensitivity for detection of left ventricular hypertrophy by electrocardiography was $11 \%$ in smokers and $15 \%$ in non-smokers by Romhilt Estes point scoring system, which was similar to above study. Using the Sokolow Lyon voltage criteria the corresponding values were $22 \%$ in smokers and $30 \%$ in non-smokers.

Lauer MS showed that Body mass index more than $30 \mathrm{~kg} / \mathrm{m}^{2}$ has been found to be associated with increased prevalence of left ventricular hypertrophy by echocardiography ${ }^{22}$.

In our study the sensitivity for the detection of left ventricular hypertrophy in over weight (BMI 26-30 $\mathrm{mg} / \mathrm{m}^{2}$ ) was $36 \%$ by Sokolow-Lyon Voltage criteria and $7 \%$ by Romhilt - Estes point scoring system, the corresponding figure in obese more than $30 \mathrm{~kg} / \mathrm{m}^{2}$ patient were $23 \%$ by Sokolow-Lyon Voltage criteria and $0.07 \%$ by Romhilt - Estes point scoring system. Obesity attenuates precordial voltage and reduces sensitivity of electrocardiography.

Melina D showed that LVM was significantly higher in alcoholic hypertensive in relation to non-alcoholic hypertensive $\mathrm{e}^{23}$. 
In our study left ventricular mass index in alcoholic was higher than in non-alcoholic. It was statistically not significant.

In our study no significant correlation between echocardiography and electrocardiography was found for detection of left ventricular hypertrophy.

\section{Conclusion}

Echocardiography is a definitely better instrument for the detection of left ventricular hypertrophy.

This study also confirms the fact that electrocardiography, because of its low sensitivity is a poor screening tool. But because of its high specificity in addition, various determinants of left ventricular hypertrophy may also independently influence the detection of left ventricular hypertrophy by electrocardiography.

\section{References}

1. Morrison Aubrey, Vijayan Anitha. Hypertension. In: Cooper DH., Krainik AJ, Reno HEL. The Washington manual of medical therapeutics. 31st Edition. Philadelphia USA: Lippincott Williams and Wilkins; 2004.p. 72-73.

2. Fisher Naomi DL, Williams Gordon $\mathrm{H}$. Hypertensive vascular disease. In: Braunwald E, Fauci A, Kasper DL. Harrison's principles of Internal medicine.16th Edition. USA: Mc Graw-Hill; 2005. p. 1463.

3. Kannel WB, Gorden T, Castelli WP, Margolis JR. Electrographically Left ventricular hypertrophy and risk of coronary heart disease. The Framingham Heart study. Ann. Intern. Med. 1970; 72: $813-22$.

4. Kannel WB, Garden T, Offatt D. Left ventricular hypertrophy by Electrocardiography: prevalence, incidence and mortality in the Framingham Heart Study. Ann. Intern. Med. 1969; 71:89-105.

5. Vason RS, Levy D. The role of Hypertension in the Pathogenesis of heart failure a clinical mechanistic overview. Arch. Intern. Med. 1996 56:1789-96.

6. Levy D, Garrison RJ, Savage DD, Kannel WB, Castelli WP. Prognostic implication of echocardiographically determined Left Ventricular Mass in the Framingham Heart Study. New Eng. J. of Med. 1990; 322:1561-6.

7. Levy D. Left ventricular hypertrophy. Epidemiological, insights from the Framingham Heart study. Drugs 1988; 35 Suppl S : $1-5$.

8. Romhilt D, Estes EH Jr. A point score systems for the Electrocardiographic diagnosis of Left ventricular hypertrophy. Am. Heart. J. 1968; 75:752.
9. Sokolow M, Lyon TP. The ventricular complex in Left ventricular hypertrophy as obtained by unipolar pericardial and limb leads. Am. Heart Journal .1949; 37:161.

10. Chobanian AV et al. Seventh report of the Joint National Committee on Prevention, detection evaluation and treatment of high Blood Pressure. Hypertension. 2003; 42:1206-52.

11. Flier J.S., Flier E.M. Obesity. In: Braunwald E, Fauci, Kasper. Harrison's principles of Internal medicine. 16th Edition. USA: Mc Graw-Hill; 2005. p. 422.

12. V.D. Maheswari, A Pillai. Influence of Smoking and Hypertension on Left Ventricular Mass. JAPI. 2000; 48:397-399.

13. Kollef Marin H. Critical care parameters and formulas. In: Cooper DH, Krainik AJ, Reno HEL. Washington Manual of Medical Therapeutics. 29th Edition Philadelphia USA; Lippincott Williams and Wilkins; 1998. p. 562

14. Wagner GS. Recording the Electrocardiogram. In: Weinberg RW, Reter RE, Geffner J. Marriott's Practical Electrocardiogram. 10th ed. Philadelphia, USA: Lippincott Williams and Wilkins. 2001.p31.

15. Feiganbaum H, Armstrong W F, Ryan $T$. Feiganbaum's Echocardiography Philadelphia USA; Lippincott Williams and Wilkins, 1994; 658-660.

16. Devereux R, Reichek N. Echocardiographic determination of Left Ventricular Mass in man: Anatomic validation of the method. Circulation. 1977; 55: $613-8$.

17. Gupta OP, Trivedi SK, Jain AP. Left Ventricular Muscle Mass by Echocardiography: Methodology. Journal of Association of Physicians of India. 1992; 40(3):179-80.

18. Reichek N, Devereux RB. Left ventricular hypertrophy Relationship of Anatomic, Echocardiographic and Electrocardiographic Findings. Circulation. 1981; 63:1391-8.

19. Nixon JV, Anderson RJ, Cohen ML. Alteration of Left Ventricular Mass and performance in patients treated effectively for thyrotoxicosis. Am. J. Med. 1979; 67:268.

20. Okin PM, Roman MJ, Devereux RB, Kligfield P. Gender differences and Electrocardiogram in Left Ventricular Hypertrophy. Hypertension. 1995; 25(2):242-9.

21. Schillaci G, Verdecchia P, Sacchi N, Vignai E, Benemio G, Porcellati C. Influence of cigarette smoking on the Electrocardiographic diagnosis of Left Ventricular Hypertrophy in arterial hypertension. G. Ital. Cardiol. 1999; 2900:34-8. 
22. Lauer MS, Anderson KM, Kannel WB, Levy D. The impact of obesity on left ventricular mass and geometry. The Framingham Heart Study. JAMA. 1991; 266(2):231-6.
23. Melina D, Colivicchi F, Melina G, Pristipino C. Left ventricular hypertrophy and diastolic dysfunction in alcohol associated hypertension. Minerva Cardioangiol. 1993; 41(7-8):293-6. 